\title{
ATTITUDES OF DENTAL INTERNS TOWARDS LEARNING COMMUNICATION SKILLS IN ALEXANDRIA UNIVERSITY
}

\author{
Sara M. Atteya ${ }^{l} B D S$, Suzan M. Saleh ${ }^{2} P h D$, Wafaa A. Essam ${ }^{2} P h D$
}

\begin{abstract}
INTRODUCTION: Effective communication not only improves dentist-patient relationships, but also enhances the patient's satisfaction towards the profession. Dental students are generally receptive to learning communication skills during their academic education and their appreciation for the value of these skills can be significantly improved with training.

OBJECTIVES: The objective of this study was to compare the attitudes of dental interns towards learning communication skills at both Faculty of Dentistry Alexandria University (public) and Pharos University (private).

MATERIALS AND METHODS: A cross-sectional study using a s questionnaire was carried out among dental interns graduated from the Faculty of Dentistry of Alexandria University (AU) and Pharos University (PU), in 2014. A self-administered, twenty-four-items, Dental Communication Skills Attitude Scale (DCSAS) that contained both positive (PAS) and negative (NAS) attitude subscales was distributed. Participants' demographic and education related variables were also recorded. Association of the positive and negative attitudes with these variables was determined using appropriate statistical tests as Pearson's chi square test, Monte Carlo Exact test, Fisher's Exact and one way ANOVA.

RESULTS: A total of 240 dental interns from Alexandria University and 162 dental interns from Pharos University participated in the study, with a response rate of $70.59 \%$ and $82.65 \%$, respectively. The mean PAS scores and NAS scores in both universities were almost the same, $52 / 65$ and $31 / 55$, respectively with no significant difference between them. These attitudes were significantly associated with certain background and education-related attributes as gender, age, parents education and previous communication skills training.

CONCLUSIONS: Despite the differences in communication skills curriculum, dental interns of both AU and PU had an overall positive and neutral attitude towards communication skills learning with no statistical significant difference between them.
\end{abstract}

KEY WORDS: communication, learning, dentist-patient relationship, dental interns, Alexandria.

1- Instructor at the Pediatric and Dental Public Health Department, Faculty of Dentistry, Alexandria University

2- Professor of Dental Public Health, Faculty of Dentistry, Alexandria University.

\section{INTRODUCTION}

Communication can be defined as the process of transmitting information and common understanding from one person to another (1). The decisive key for the arrangement of a productive patient-doctor relationship is professional communication (2). In the dental field, dentists and other health care providers should learn to appropriately communicate with their patients (3). Evidence from the literature has shown that effective dentist-patient communication not only improves dentist-patient relationships and promotes positive health outcomes, but also enhances the patient's satisfaction towards the profession, maximizes use of health care resources and helps reduce patients' complaints. It is the ability to communicate effectively with patients, use active listening skills, gather and impart information efficiently, handle patients' emotions sensitively, as well as demonstrate empathy, rapport, ethical awareness, and professionalism (4).

A common description of attitudes is a mixture of beliefs, thoughts and feelings which predispose a person to respond, in a positive or negative way, to objects, people, processes or institutions (5). If a person's attitude is changed, his or her behavior may change as well (6). Several variables are assumed to affect attitudes towards communication skills such as demographic variables, experience within the clinical setting and the appreciation of patient-oriented care (7).

In 2008, the American Dental Education Association (ADEA) House of Delegates approved communication and interpersonal skills as one of the domains of competencies that should be fulfilled by graduated general dentists (8). It was found that dental students are generally receptive to learning communication skills and their appreciation for the value of these skills can be significantly improved with training (9). For today's dental schools, a further crucial question is how and at what stage; communication skills' training can best be integrated into an already crowded curriculum (10).

Different attitude scales for measuring communication skills were reported in the literature. The Communication Skills Attitudes Scale (CSAS), used to measure students' attitudes towards learning communication skills during medical school, was tested on 490 Nottingham and Leiceste medical students. Authors found that attitudes towards communication skills learning were significantly associated with a number of demographic and education-related characteristics such as age, gender, ethnicity, and first language. (11). Students' attitude towards learning communication skills in relation to demographic variables, metacognitive skills, the appreciation of patient-oriented care and to learning curriculum in Sweden and German medical schools was also explored. Results showed that a positive attitude towards learning communication skills was predicted by a caring patient orientation, self-regulation of learning strategies, and female gender. Students from a traditional curriculum were least interested in learning communication skills (12).

In dentistry, few studies were carried out regarding learning communication skills. Forty U.S. and Canadian dental schools were surveyed and only one-third reported having a course that specifically focused on teaching communication skills (13). Furthermore, a study was 
conducted at two consecutive dental school classes, at New Jersey Dental School, using the Arizona Clinical Interviewing Rating Scale (ACIR). Authors reported that dental students showed significant improvement in communication skills after two training sessions (14).

Then, Laurence et al. (15) attempted to adapt the 26 item Communication Skills Attitude Scale (CSAS), originally developed for medical students, to be used among dental students in a dental school, in Washington. The final 24 'item scale had good internal consistency, and the study addressed four important factors namely Learning, Importance, Quality, and Success. The authors concluded that the CSAS modified for dental students, or DCSAS, is a useful tool to assess attitudes towards learning communication skills among dental students.

Furthermore, the factors contributing to the attitudes of medical and dental students in University of Zimbabwe towards the learning of Communication Skills were assessed. Authors found that Positive Attitude Scores of the $4^{\text {th }}$ year students were significantly higher than those of year 1 and 2. Positive Attitude Scores were strongly influenced by gender, age, and year of study (16).

A systematic review of journal articles published in Western Europe, the United States, and New Zealand examined the scope and quality of communication skills training for dental students. They concluded that no previous studies had explored interpersonal communication skills intra-operatively or postoperatively. Furthermore, cultural background and other demographic variables can influence the interaction between dental students and patients. Such findings provided a fertile background and strong rationale for additional research on communication skills among dental students and practitioners (17).

In Egypt, no previous studies were carried out to explore neither the attitude of dental students towards learning communication skills, nor the curriculum taught. Thus, the aim of this study was to compare the attitudes of recently graduated dentists in the Faculty of Dentistry, Alexandria University (AU) and Pharos University (PU) towards teaching and learning communication skills, in relation to demographic and education-related characteristics as well as communication skills curriculum, assuming no differences between both universities in this issue.

\section{MATERIALS AND METHODS}

The current study was a cross sectional, analytical design aiming to compare dental interns' attitudes towards learning communication skills in both AU and PU using a close ended survey questionnaire based on literature review (15). The target population was all available dental interns who were graduated at the academic year 2012-2013 from both universities.

The study was conducted at the various settings, within Alexandria governorate, where the newly graduated dentists from both Universities were practicing their internship program. Those settings included the outpatients' dental clinics at the Alexandria Faculty of Dentistry and Pharos Faculty of Dentistry in addition to eleven Ministry of Health $(\mathrm{MOH})$ facilities. The $\mathrm{MOH}$ facilities included eight hospitals namely Abu-Qir, Sharq El-Madina, Wingat, ElGomhoureya, Ras El-Tin, El-Agami, El-Amreya, and Borg El-Arab public hospitals; as well as two dental research centers namely; Semouha and Moharam Bek dental research centers. In addition to Sidi Bishr Bahari Family Health Center.

The approval of the Dental Research Ethics Committee at the Alexandria Faculty of Dentistry was first obtained. In addition; verbal acceptance of the graduated dentists to participate in the study was sought, after detailed explanation of the objectives of the research, in order to gain their trust and confidence. Returning the completed questionnaire was considered an implied consent indicating the willingness of interns to participate in the study (18).

An updated list of the interns' distribution in the different $\mathrm{MOH}$ facilities was obtained from the Directorate of Health Affairs after approval of the head of the Directorate to approach interns.

Data collection took from July $14^{\text {th }}$ to October $31^{\text {st }}, 2014$. In order to ensure the participation of as many interns as possible, each $\mathrm{MOH}$ facility was visited three to four times throughout the study period, whereas each outpatient's clinics in different clinical departments in Alexandria Faculty of Dentistry and Pharos Faculty of Dentistry were approached five times as a large number of interns, about 100 were spending most of their internship period there.

The questionnaire consisted of two main sections as follows:

- The first section included demographic and educationrelated characteristics of the participants such as gender, age, parents' education, parents' occupation, whether parents working in health services or not, self-rating of participants' communication ability, any previous training in communication skills and participants' opinion about their communication skills.

- The second section has assessed the attitude of the participants towards learning communication skills using the Dental Communication Skills Attitude Scale (DCSAS) (15), which is an adapted form of the original Communication Skills Attitude Scale developed by Rees et al. for medical students (14). DCSAS comprises 24 statements and includes two scales, the positive attitude scale and the negative attitude scale. The Positive Attitude Scale (PAS) refers to students' appreciation of communication skills as an academic subject, as well as to their beliefs about respect for the patients' rights and about the importance of communication with patients and colleagues. It contains 13 items. The Negative Attitude Scale (NAS), on the other hand, comprises 11 items that refer to negative aspects of communication skills instruction. Responses were analyzed on a five-point Likert scale ranging from 1 (strongly disagree) to 5 (strongly agree). So, for all questions, positive attitude score ranged from 13 to 65 and negative attitude score ranged from 11 to 55 .

The DCSAS comprises four factors; Learning, Importance, Quality and Success. Learning included ten items (all of which are positive attitude). This factor contains both utilitarian and ethical aspects of dental practice. The attitude score for learning range from 10 to 50 . Importance comprised six items; all of them were negatively phrased. This factor reflects both the complexity of communication and the difficulty in achieving mastery. The attitude score for importance range from 6 to 30 . Quality included four items ( 2 are positive attitude and 2 are negative). This factor contains statements about the process of learning good communication skills as well as equating the value of communications on parity with other dentistry 
skills and knowledge. The attitude score for learning range from 4 to 20. Success also included four items (3 are negative attitude and one is positive). The factor contains statements about the process as well as the positive effects of communications skills in the journey towards dental school success. The attitude score for learning range from 4 to 20 (15).

In addition, the study also aimed to analyze communication skills curriculum in both the Faculty of Dentistry AU and PU. To fulfill this aim, the researcher has contacted the course director responsible for teaching communication skills in both universities and has requested the course specification. Course analysis was established based on the following characteristics 1) the extent to which interpersonal communication skills are taught (timing) and where they are taught in the curriculum; 2) what content is taught; 3) what teaching methodology is used; 4) what approaches to evaluation are utilized; and 5) the background of course instructors (19).

Data were collected, revised, coded and fed to statistical software IBM SPSS version 20. Descriptive statistics were used to describe demographic and education-related variables of the study participants. Pearson's chi square test, Monte Carlo Exact test and Fisher's Exact test were used to test the differences in demographic and education-related characteristics between the two groups of dental interns. Independent samples t-test and One Way ANOVA were used to assess relationships between dependent (PAS and NAS scores) and independent (demographic and educationrelated characteristics) variables for Alexandria University and Pharos University dental interns separately. Multiple stepwise linear regression was used to determine significant predictors for positive and negative attitudes for both universities.

\section{RESULTS}

\section{Clinical evaluation}

Data retrieved from both Universities indicated that the number of dental interns accounted for 340 interns (201 females and 139 males) from AU and 196 interns (101 females and 95 males) from PU. A small number of interns refused to respond to the questionnaire (around 70 from $\mathrm{AU}$ and 34 from PU), in addition to those who were having their internships outside Alexandria governorate (around 40 from AU). Therefore, only a total of 240 dental interns from AU (141 females and 99 males) and 162 dental interns from PU ( 85 females and 77 males) participated in the study, with a response rate accounting for $70.59 \%$ and $82.65 \%$, respectively.

Age of the dental interns ranged from 21 to 37 years with a mean age of $23.21( \pm 1.02)$ years in AU and a mean age of $23.47( \pm 1.10)$ years in PU, whereas the higher percent of the study sample composed of females accounting for $58.8 \%$ and $52.5 \%$ in AU and PU respectively. The majority of the study sample had both father and mother education at University level (91.3\% and 88.8\% respectively) in AU and (94.4\% and 93.2\% respectively) in PU. Most of the study participants in AU did not have parents working in health services $(66.3 \%)$, compared to $49.4 \%$ in PU. Regarding dental interns' ratings of their own communication skills, around $63.3 \%$ in $\mathrm{AU}$ and $54.3 \%$ in $\mathrm{PU}$ have rated themselves as good. The higher percent of the study sample in both $\mathrm{AU}(68.8 \%)$ and PU (54.3\%) did not receive any previous training in communication skills and among those who received training; it was mainly through lectures (44\%) and (46\%) and training workshop (42.7\%) and (34.2\%) in AU and PU, respectively. Finally, most of the dental interns thought that their communication skills needed improvement whether in $\mathrm{AU}(84.2 \%)$ or in PU (74.1\%).

Analysis of the data on students' attitudes towards learning communication skills in each of the DCSAS four factors showed that the mean attitude scores was almost the same in both universities showing no statistical significant difference (Figure 1).

Furthermore, both mean positive and negative attitude scores showed no statistical significant difference between the two universities as well (Figure 2).

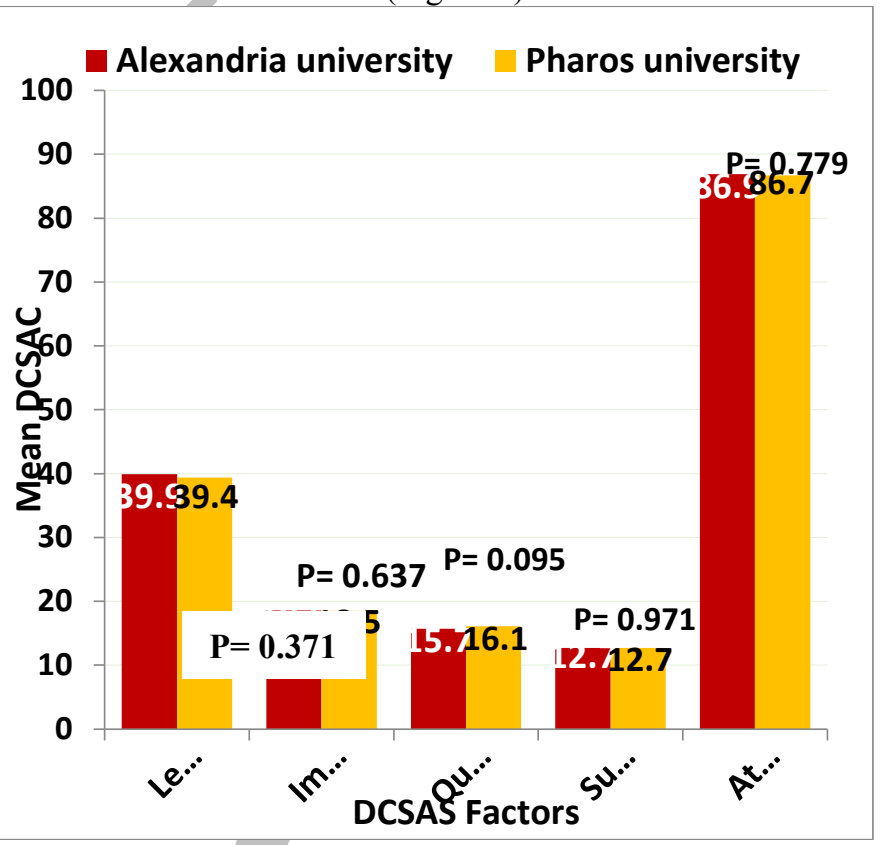

Figure 1: Distribution of the means of attitude score in the four DCSAS factors in both Alexandria and Pharos Universities.

\section{Alexandria university $\square$ Pharos university}

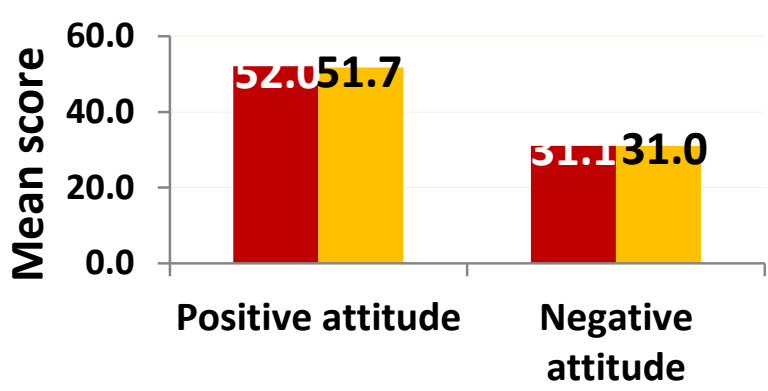

Attitude

Figure 2: Distribution of the Means of positive and negative attitude scores in both Alexandria and Pharos Universities (2014).

The mean scores of the PAS for the study participants, at AU and PU were 52 and 51.7 respectively. Of the relationships explored between the positive attitude subscale and the demographic and education-related characteristics, only two were found to be statistically significant in AU, namely; self-rating of dental interns' own communication ability $(\mathrm{p}=0.013)$ and previous training in communication skills $(p=0.001)$. Meanwhile, only five independent variables were found to be 
statistically significant in PU, which were; age of participants $(p=0.002)$, their gender $(p=0.008)$, self-rating of dental interns' own communication ability $(p=0.013)$, previous training in communication skills $(p=0.001)$, type of communication skills training they received $(p=0.006)$ and the need for participants' communication skills improvement $(\mathrm{p}=0.032)$ (Table 1$)$.

The stepwise multiple linear regression model of the significant independent variables with the dependent variable PAS score by university is displayed in table 2.

Table 1: Mean and standard deviation of the positive attitude scores subscale (PAS) in relation to demographic and education-related characteristics of study participants in Alexandria and Pharos Universities (2014).

\begin{tabular}{|c|c|c|c|c|c|c|c|}
\hline \multirow{3}{*}{\multicolumn{2}{|c|}{ Characteristics }} & \multicolumn{3}{|c|}{ Alexandria university } & \multicolumn{3}{|c|}{ Pharos university } \\
\hline & & \multicolumn{3}{|c|}{ Positive attitude } & \multicolumn{3}{|c|}{ Positive attitude } \\
\hline & & Mean & SD & $\begin{array}{l}\text { Test of } \\
\text { significance }\end{array}$ & Mean & SD & $\begin{array}{l}\text { Test of } \\
\text { significance }\end{array}$ \\
\hline \multirow{3}{*}{ Age } & $21-$ & 51.5 & 7.7 & \multirow{3}{*}{$\mathrm{F}=0.25(0.778)$} & 47.5 & 6.2 & \multirow{3}{*}{$\mathrm{F}=6.3(0.002)^{*}$} \\
\hline & $23-$ & 52.2 & 5.4 & & 52.5 & 6.2 & \\
\hline & $25+$ & 52.1 & 7.5 & & 51.9 & 6.6 & \\
\hline \multirow{2}{*}{ Gender } & Female & 52.5 & 6.0 & \multirow{2}{*}{$\mathrm{t}=1.8(0.156)$} & 53.0 & 5.8 & \multirow{2}{*}{$\mathrm{t}=2.9(0.008)^{*}$} \\
\hline & Male & 51.4 & 6.2 & & 50.3 & 6.9 & \\
\hline \multirow{4}{*}{ Father education } & Illiterate & 48.1 & 10.3 & \multirow{4}{*}{$\mathrm{F}=1.1(0.349)$} & 59.0 & 7.1 & \multirow{4}{*}{$\mathrm{F}=1.5(0.209)$} \\
\hline & Basic & 51.5 & 2.1 & & 55.6 & 3.6 & \\
\hline & Secondary & 53.2 & 3.9 & & 51.5 & 4.9 & \\
\hline & University & 52.1 & 6.0 & & 51.5 & 6.5 & \\
\hline \multirow{4}{*}{ Mother education } & Illiterate & 52.3 & 4.1 & \multirow{4}{*}{$\mathrm{F}=0.56(0.645)$} & 54.7 & 9.0 & \multirow{4}{*}{$\mathrm{F}=2.3(0.079)$} \\
\hline & Basic & 57.0 & 5.7 & & 55.3 & 4.0 & \\
\hline & Secondary & 51.1 & 7.3 & & 44.5 & 9.0 & \\
\hline & University & 52.0 & 6.1 & & 51.7 & 6.4 & \\
\hline \multirow{2}{*}{ Parents working in health services } & No & 52.1 & 6.2 & \multirow{2}{*}{$\mathrm{t}=0.07(0.794)$} & 52.0 & 6.7 & \multirow{2}{*}{$\mathrm{t}=0.09(0.568)$} \\
\hline & Yes & 51.9 & 5.9 & & 51.4 & 6.3 & \\
\hline \multirow{4}{*}{ What is your self-rating of communication ability } & Excellent & 53.4 & 5.7 & \multirow{4}{*}{$\mathrm{F}=3.7(0.013)^{*}$} & 52.5 & 6.3 & \multirow{4}{*}{$\mathrm{F}=1.7(0.164)$} \\
\hline & Good & 52.5 & 5.4 & & 51.6 & 6.5 & \\
\hline & Average & 50.0 & 7.1 & & 49.8 & 6.7 & \\
\hline & Poor & 46.7 & 16.1 & & 58.5 & 4.9 & \\
\hline \multirow{2}{*}{ Did you receive any training in communication skills } & No & 51.1 & 6.3 & \multirow{2}{*}{$\mathrm{t}=3.6(0.001)^{*}$} & 50.1 & 6.3 & \multirow{2}{*}{$\mathrm{t}=3.6(0.001)^{*}$} \\
\hline & Yes & 54.1 & 4.9 & & 53.5 & 6.2 & \\
\hline \multirow{3}{*}{ If yes, specify type } & Lectures & 54.0 & 5.0 & \multirow{3}{*}{$\mathrm{F}=0.10(0.958)$} & 51.3 & 5.6 & \multirow{3}{*}{$\mathrm{F}=5.2(0.006)^{*}$} \\
\hline & $\begin{array}{l}\text { Continuous education } \\
\text { course }\end{array}$ & 54.3 & 6.6 & & 57.1 & 5.0 & \\
\hline & Training workshop & 54.1 & 4.4 & & 54.6 & 6.6 & \\
\hline \multirow{2}{*}{ Your communication skills need improvement } & No & 50.5 & 5.2 & \multirow{2}{*}{$\mathrm{t}=1.5(0.088)$} & 49.8 & 7.0 & (-20 (0020)* \\
\hline & Yes & 52.3 & 6.2 & & 52.3 & 6.2 & $2.2 .2(0.002)$ \\
\hline
\end{tabular}

$\mathrm{F}=$ one way Anova test

$\mathrm{t}=$ Independent samples t-test $* \mathrm{P}<0.05$ (significant)

Table 2: Multiple stepwise linear regression: dependent variable positive attitude subscale (PAS) score by university

\begin{tabular}{|c|c|c|c|c|c|}
\hline \multirow{2}{*}{ Predictors of positive attitude } & \multicolumn{2}{|c|}{ Unstandardized Coefficients } & \multirow[t]{2}{*}{ Standardized Coefficients (Beta) } & \multirow[t]{2}{*}{$\mathbf{t}$} & \multirow[t]{2}{*}{ Sig. } \\
\hline & B & SE & & & \\
\hline $\begin{array}{l}\text { Alexandria university } \\
\text { (Constant) } \\
\text { Receive any training in communication skills } \\
\text { Self-rating of communication ability } \\
\text { Your communication skills need improvement }\end{array}$ & $\begin{array}{r}53.72 \\
2.44 \\
-2.15 \\
2.44\end{array}$ & $\begin{array}{l}1.44 \\
0.83 \\
0.63 \\
1.09\end{array}$ & $\begin{array}{c}0.19 \\
-0.22 \\
0.15\end{array}$ & $\begin{array}{l}37.33 \\
2.95 \\
-3.42 \\
2.24\end{array}$ & $\begin{array}{r}0.001^{*} \\
0.004^{*} \\
0.001^{*} \\
0.026^{*}\end{array}$ \\
\hline $\begin{array}{l}\text { Pharos university } \\
\text { (Constant) } \\
\text { Receive any training in communication skills } \\
\text { Your communication skills need improvement } \\
\text { Male gender } \\
\text { Age } \\
\text { Father education }\end{array}$ & $\begin{array}{c}37.35 \\
2.95 \\
2.62 \\
-2.67 \\
0.97 \\
-1.98\end{array}$ & $\begin{array}{c}10.67 \\
0.95 \\
1.08 \\
0.95 \\
0.43 \\
0.98\end{array}$ & $\begin{array}{r}0.23 \\
0.18 \\
-0.21 \\
0.16 \\
-0.15\end{array}$ & $\begin{array}{c}3.50 \\
3.11 \\
2.43 \\
-2.81 \\
2.24 \\
-2.03\end{array}$ & $\begin{array}{l}0.001^{*} \\
0.002^{*} \\
0.016^{*} \\
0.006^{*} \\
0.027^{*} \\
0.044^{*}\end{array}$ \\
\hline
\end{tabular}

B: Regression coefficient

Sig: Significant predictor $(\mathrm{P}<0.05)$ 
Regarding receiving any training in communication skills, those who were previously trained had 2.44 and 2.95 higher PAS in both AU and PU, respectively compared to those who were not. Similarly, students who reported they needed improvement in communication skills had 2.44 and 2.62 higher PAS in AU and PU, respectively, compared to their colleagues. As for self-rating of communication skills ability, the increase in score by one degree was associated with decrease in PAS by 2.1 score among AU participants. In PU, female had 2.7 higher mean PAS score than male, and an increase in age by one year had 1 more PAS score. While students whose fathers were university educated had a one-point higher PAS compared to students whose father were illiterate. Based on the regression coefficient, selfrating of communication ability and previous training in communication skills were found to have the strongest influence on PAS scores of the participants in AU and PU, respectively.

As for the NAS scores, the overall mean NAS for the study participants at AU and PU, was 31.1 and 31, respectively. Of the relationships explored between the NAS and the demographic and education-related characteristics, only two were found to be statistically significant in AU, namely; self-rating of dental interns' own communication ability $(p=0.001)$ and previous training in communication skills $(\mathrm{p}=0.012)$. Meanwhile, only four of the independent variables were found to be statistically significant in PU, namely; age of participants $(\mathrm{P}=0.014)$, father education of participants $(\mathrm{P}=0.009)$, previous training in communication skills $(\mathrm{p}=0.037)$ and type of communication skills training $(p=0.002)$ (Table 3$)$.

The stepwise multiple linear regression model of the significant independent variables with the dependent variable NAS score by university is shown in table 4 .

Those who received previous training had 1.64 and 1.61 less NAS scores in both AU and PU, respectively compared to those who were not. In AU, self-rating of dental interns' own communication ability, the increase in score by one degree was associated with increase in NAS by 1.23 . However, when the mother education was increased by one category, the NAS score was decreased by 1.06. In PU, when the father education was increased by one category, the NAS score was decreased by 1.81 , and an increase in age by one had less NAS score by 0.70 . Based on the regression coefficient, self-rating of communication ability and father education were found to have the strongest influence on NAS scores of AU and PU participants, respectively.

The percentage distribution of participants' attitude in each DCSAS factor in Alexandria and Pharos Universities is displayed in figures 3 and 4.

Table 3: Mean and standard deviation of the negative attitude scores subscale (NAS) in relation to demographic and education-related characteristics of study participants in Alexandria and Pharos Universities (2014)

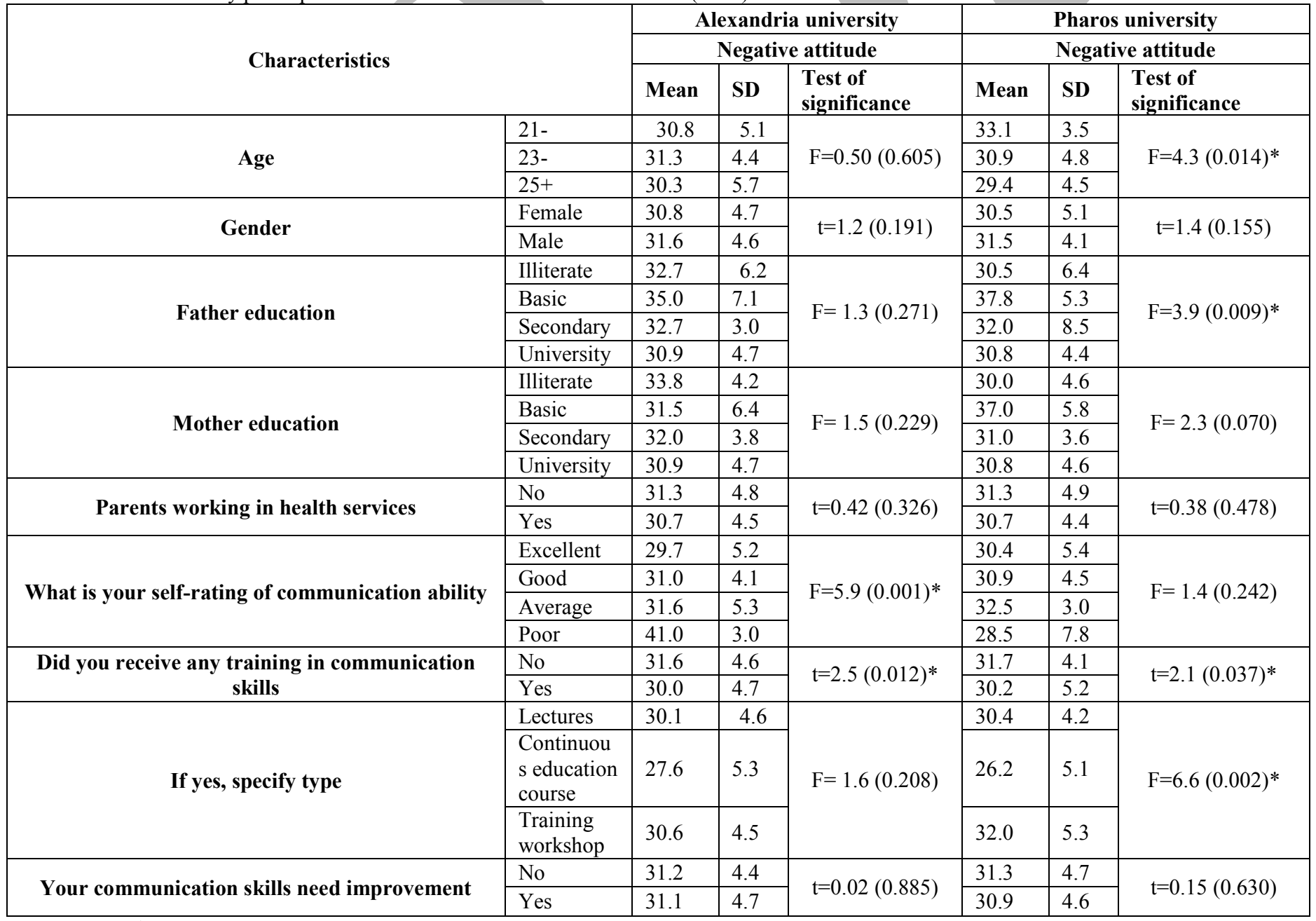

$\mathrm{F}=$ one way Anova test

$\mathrm{t}=$ Independent samples t-test $* \mathrm{P}<0.05$ (significant) 
Table4: Multiple stepwise linear regression: dependent variable negative attitude subscale (NAS) score by university (2014)

\begin{tabular}{|c|c|c|c|c|c|c|}
\hline \multirow{2}{*}{ Predictors of negative attitude } & \multicolumn{2}{|c|}{ Unstandardized Coefficients } & \multicolumn{2}{|c|}{ Standardized Coefficients (Beta) } & \multirow{2}{*}{$\mathbf{t}$} & \multirow{2}{*}{ Sig. } \\
\hline & B & & SE & & & \\
\hline \multicolumn{7}{|l|}{ Alexandria university } \\
\hline (Constant) & 33.05 & & 2.05 & & 16.10 & $0.001^{*}$ \\
\hline Self-rating of communication ability & 1.23 & & 0.47 & 0.17 & 2.64 & $0.009 *$ \\
\hline Receive any training in communication skills & -1.64 & & 0.64 & -0.16 & -2.57 & $0.011 *$ \\
\hline Mother education & -1.06 & & 0.45 & -0.15 & -2.37 & $0.019 *$ \\
\hline \multicolumn{7}{|l|}{ Pharos university } \\
\hline (Constant) & 55.19 & 7.8 & & & 7.03 & $0.001 *$ \\
\hline Receive any training in communication skills & -1.61 & 0.7 & & -0.17 & -2.28 & $0.024 *$ \\
\hline Father education & -1.81 & 0.7 & & -0.19 & -2.49 & $0.014^{*}$ \\
\hline Age & -0.70 & 0.3 & & -0.17 & -2.20 & $0.029^{*}$ \\
\hline
\end{tabular}

B: Regression coefficient

Sig: Significant predictor $(\mathrm{P}<0.05)$

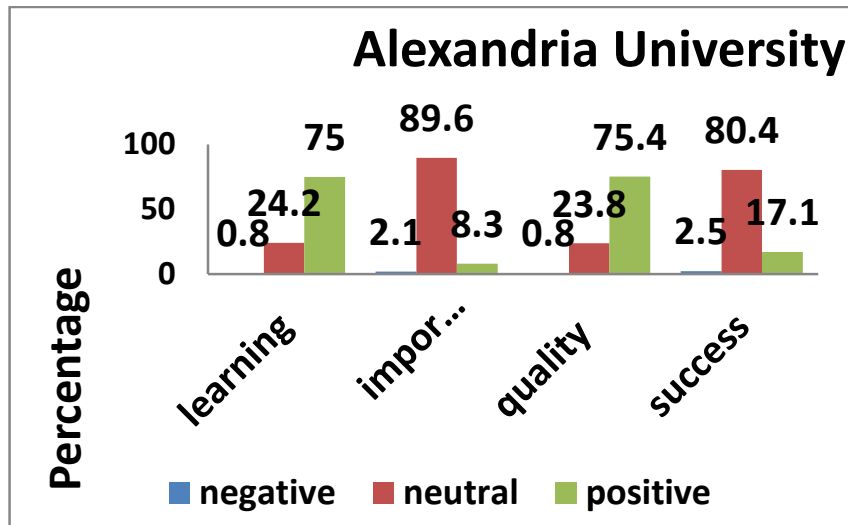

Figure3: Distribution of the percentage of different participants' attitude in each DCSAS factor in Alexandria University (2014).

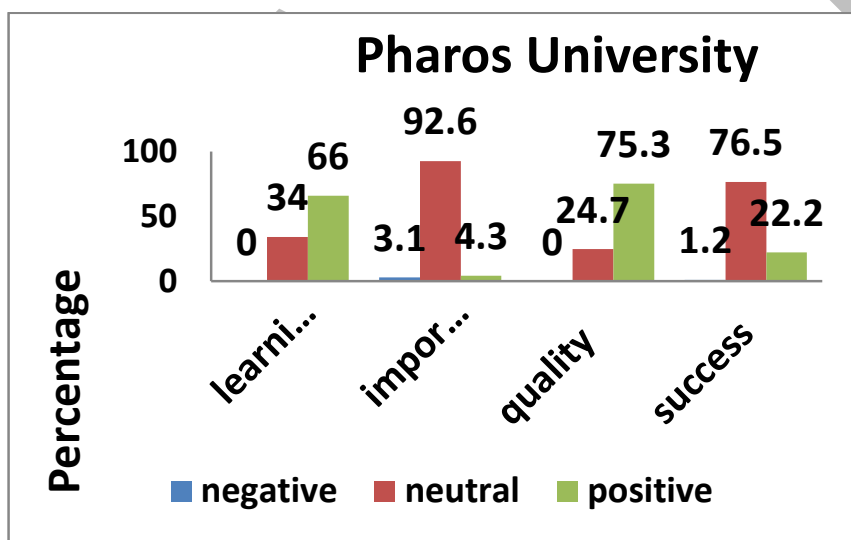

Figure4 : Distribution of the percentage of different participants' attitude in each DCSAS factor in Pharos University (2014).

Regarding the learning factor, the highest percent of participants had positive attitude in both AU and PU, 75.0\% and $66.0 \%$, respectively. As for the quality factor, about three quarter of the study participants had positive attitude in both $\mathrm{AU}$ and $\mathrm{PU}, 75.4 \%$ and $75.3 \%$, respectively. Neutral attitudes have been reported by study sample concerning the importance and success factors in both $\mathrm{AU}$ and PU, where their percentages were, $89.6 \%$ and $92.6 \%$, and $80.4 \%$ and $76.5 \%$, respectively. In addition, there was no statistical significant difference between the two Universities regarding the four DCSAS factors.

Finally, analysis of communication skills curriculum in both universities was done to compare between teaching aspects of communication skills in AU and PU. In AU, teaching communication skills was only through two lectures as an integral part of the dental public health curriculum for 4th year dental students. Regarding the evaluation methods, AU used oral and written exams. The course is taught by staff members of dental public health department. In PU, on the other hand, a separate course for communication skills was taught to the second year dental students before clinical practice in 3rd year which allowed them to experience communication and early patient contact in a professional setting. The Pharos University course used more didactic teaching hours that accounted for 15 lectures compared to Alexandria University course, in addition to experimental methods of learning, such as oral discussions, impromptu speeches, debates and oral presentations. Regarding the evaluation methods, they mainly depended on oral examination and quizzes. The course is taught by staff members from business department in the Faculty of Commerce.

\section{DISCUSSION}

Despite a substantial amount of literature regarding communication skills of dental students, there is a dearth of evidence on their attitudes towards communication skills learning (20). The patient-dentist communication is deemed a vital clinical skill. As in other health care settings, the relationship between dentist and patient has a considerable impact on successful treatment and patient satisfaction (21).

The present study used the adapted version 24'item modified DCSAS scale because of its high internal consistency in assessing their attitudes towards learning communication skills in both AU and PU (15). The responses were analyzed on a five-point Likert scale ranging from 1 (strongly disagree) to 5 (strongly agree). However, most of the participants favored the neutral response that resulted into an overall neutral and positive attitude scale rather than negative and positive scale.

A reasonable response rate was obtained as high as 70.59 $\%$ in $\mathrm{AU}$ and $82.65 \%$ in PU, compared to $94.4 \%$ in the University of Malaya and $83.3 \%$ in the University of Kebangsaan Malaysia (20) and to $88 \%$ at the Dunedin University in New Zealand (22). Thus, implying that survey results may be representative of the intern population of the studied faculties (AU and PU). 
Age was found to have a significant relationship with PAS and NAS scores among Pharos interns. As age increased, PAS scores increased (Tables 1,3), suggesting that older interns had more positive attitudes towards communication skills learning than younger. A possible explanation for this finding is that older interns at PU may have utilized their communication skills abilities in a wide variety of settings outside their academic education, as in previous training. As a result, they started to recognize the values, relevance and implications of good communication skills. This is consistent with several previous studies (16, 23-25). However, this is in contrast to the findings of Nor et. al (20) and Rees and Sheard (26) who reported that younger students were more prone to learn communication skills and attributed this observation to their lower experience in communicating with people they do not know.

Gender was also found to have statistically significant relationship with PAS scores among Pharos interns. Female interns had higher PAS scores compared to male interns (Tables 1,2). This finding is consistent with earlier research conducted by Nor et al. (20), Rees and Sheard (26), Wright et al. (27), Batenburg and Smal (28), as well as Kassebaum and Culter (29) who also reported similar trend. It may be that the art of communication comes more naturally from a female and as a student she would be more likely to appreciate the science of dentist-patient communication (30). However, a study in Nepal on a group of medical students found no significant association between gender and positive attitudes towards communication skills learning (25).

The present study showed no significant relation between parents working in health care system and their children PAS and NAS scores in both universities (Tables 1,3). A possible explanation would be that communication skills were not previously taught to the parents as a part of their undergraduate curriculum. This might be the reason for not appreciating the importance of this subject. However, this is in contrast with other findings in the literature that revealed a significant relation between parents working in health care system and their children's PAS and NAS scores $(24,26,29)$.

Regarding the relationship between attitudes and education-related variables, there was a significant relationship between previous training in communication skills and PAS and NAS scores, in both Alexandria and Pharos universities. Whereby, receiving previous training in communication skills, increased the interns' PAS scores and decreased their NAS scores (Tables 2,4). This may be attributed to the positive effect of the training programs attended, which raised the value of studying this subject among them. This result is consistent with other findings from literature; Doherty et al. (31), Langille et al. (32) and Liddell and Davidson (34). On the other hand, the current results are not in agreement with those of Rees and Sheard (35) as well as Shankar et al. (25) who suggested that students may be developing more negative attitudes towards communication skills learning as a result of attending communication skills courses.

Responses to the question "Do your communication skills need improvement" were shown to have statistically significant relationship with PAS scores in both Alexandria and Pharos dental interns (Tables 1,2). This finding suggests that interns who felt their communication skills were lacking, valued the opportunities afforded by communication skills learning than those who felt their communication skills did not need improvement, thus had more PAS. This is consistent with other studies in the literature $(26,34)$. Although they contradict with one previous study suggesting that students with better perceived communication skills have more positive attitudes towards communication skills learning than students with poorer communication skills (24).

The results of the present study showed no statistically significant difference neither between the means of attitude scores of dental interns in both universities, in all the four factors of the DCSAS nor in the mean PAS scores and NAS scores, despite the differences found in the communication skill course between the two universities (Figures 1,2). This finding is consistent with the study of Nor et al. (20) in Malaya University, who found that the lengthy exposure to communication skills learning, particularly in the clinical year when students are more concerned with acquiring clinical competence, had caused them to lose some interest. This possible explanation was also suggested by another study that found students' attitudes towards learning could become negative as a result of prolonged teaching (30). However, this finding was in contrast with Rees and Sheard (26), who found that different communication skills courses had statistically significant association with both participants' PAS and NAS scores and attributed that to differences in teaching methods and the students' different levels of experience regarding communication skills learning at the time of survey completion.

Finally, dental interns, of both universities, possessed an overall neutral and positive attitude towards learning communication skills without significant difference between them. The greatest percentage of dental interns in both universities had positive attitude towards learning and quality factors, while they had neutral attitude towards importance and success factors of the DCSAS. Given these findings, dental interns lack the knowledge about the importance of learning communication skills and that they thought that their ability to pass exams will get them through dental school rather than their ability to communicate with patients. So, dental schools educators should pay more attention to the importance of communication skills for the dentists with regards to their clinical work and that success in communicating with patients is the key to success in dental treatment as well as its outcome measures, when teaching courses emphasizing communication skills. Furthermore, there are no formal training sessions in communication skills during the clinical years of both universities which may be partly responsible for the neutral attitude of dental interns.

\section{CONCLUSIONS}

1. Dental interns of both AU and PU have an overall positive and neutral towards communication skills learning.

2. Positive attitudes towards communication skills learning were mostly associated with female gender and previous training in communication skills.

3. Despite the differences in communication skills curriculum, there was no statistically significant difference in interns' attitude.

\section{CONFLICT OF INTEREST}

The authors declared that they have no conflicts of interest. 


\section{REFERENCES}

1. Keyton J. Communication and organizational culture: A key to understanding work experiences. California: Sage Publications; 2010: 16.

2. Street RL Jr, Makoul G, Arora NK, Epstein RM. How does communication heal? Pathways linking clinicianpatient communication to health outcomes. Patient Educ Couns 2009; 74: 295-301.

3. Hottel TL, Hardigan PC. Improvement in the interpersonal communication skills of dental students. $\mathrm{J}$ Dent Educ 2005;69: 281-4.

4. Hannah A, Millichamp CJ, Ayers KMS. A communication skills course for undergraduate dental students. J Dent Educ 2004; 68: 970-7.

5. Brown G, Manogue M, Rohlin M. Assessing attitudes in dental education: Is it worthwhile? B Dent J 2002; 193: 703-70

6. Krupat E, Hiam CM, Fleming MZ, Freeman P. Patientcenteredness and its correlates among first year medical students. Int J Psychiatry Med 1999; 29: 347-56.

7. Petty RE, Wegener DT, Fabrigar LR. Attitudes and attitude change. Annu Rev Psychol 1997; 48: 609-47.

8. American Dental Education Association. ADEA competencies for the new general dentist (as approved by the 2008 ADEA House of Delegates). J Dent Educ 2012; 76: $891-4$

9. Wagner J, Arteaga S, D'Ambrosio J, Hodge CE, Ioannidou $\mathrm{E}$, Pfeiffer $\mathrm{CA}$, et al. A patient-instructor program to promote dental students' communication skills with diverse patients. J Dent Educ 2007 ;71: 155460

10. General Dental Council. The first five years. The undergraduate curriculum. 3rd ed (Interim report). London: General Dental Council; 2008

11. Rees C, Sheard C, Davies S. The development of a scale to measure medical students' attitudes towards communication skills learning: The Communication Skills Attitude Scale (CSAS). Med Educ 2002; 36: 1417.

12. Lumma-Sellenthin A. Students' attitudes towards learning communication skills: correlating attitudes, demographic and meta-cognitive variables. Int $\mathrm{J}$ Med Educ 2012; 3: 201-8

13. Yoshida T, Milgrom P, Coldwell S. How do U.S. and Canadian dental schools teach interpersonal communication skills? J Dent Educ 2002; 66: 1281-8.

14. Broder HL, Janal M. Promoting interpersonal skills and cultural sensitivity among dental students. J Dent Educ 2006; 70: 409-16.

15. Laurence B, Bertera EM, Feimster T, Hollander R, StromanC. Adaptation of the Communication Skills Attitude Scale (CSAS) to Dental Students. J Dent Educ 2012; 76: 1629-38.

16. Kahari L, Takavarasha P. A study of University of Zimbabwe Medical Student's Attitudes towards the teaching and learning of communication skills. Int $\mathrm{J}$ of Adv Res 2013; 1: 35-42

17. Carey J, Madill A, Manogue M. Communication skills in dental education: a systematic research review. Eur J Dent Educ 2010; 14: 69-78.

18. Sherman JJ, Cramer A. Measurement of changes in empathy during dental school. J Dent Educ 2005; 69: 33845 .
19. Yoshida T, Milgrom P, Coldwell S. How do U.S. and Canadian dental schools teach interpersonal communication skills? J Dent Educ 2002; 66: 1281-8.

20. Nor NA, Yusof ZY, Shahidan MN. University of Malaya dental students' attitudes towards communication skills learning: implications for dental education. J Dent Educ 2011; 75: 1611-9.

21. Kurtz SM. Doctor-patient communication: principles and practices. Canadian J Neurol Sci 2002; 29: S23-S9.

22. Hannah A, Millichamp CJ, Ayers KM. A communication skills course for undergraduate dental students. J Dent Educ 2004; 68: 970-7.

23. Rees C, Garrud P. Identifying undergraduate medical students' attitudes towards communication skills learning: a pilot study. Med Teach 2001; 23: 400-6.

24. Khashab SS. Attitudes of Alexandria Medical Students towards Communication Skills Learning. J Egypt Public Health Assoc 2006; 81: 355-72.

25. Shankar P, Dubey A, Balasubramanium R, Dwivedi N. Student attitude towards communication skills learning in a Caribbean medical school. Australas Med J 2013; 6: 466-75.

26. Rees C, Sheard C. The relationship between medical students' attitudes towards communication skills learning and their demographic and education-related characteristics. Med Educ 2002; 36: 1017-27.

27. Wright KB, Bylund C, Ware J, Parker P, Query JL, Baile W. Medical student attitudes toward communication skills training and knowledge of appropriate providerpatient communication: a comparison of first-year and fourth-year medical students. Med Educ 2006; 11: 1-10.

28. Batenburg V, Smal J. Does a communication course influence medical students' attitudes? Med Teach 1997; 19: $263-9$

29. Kassebaum DG, Cutler ER. On the culture of student abuse in medical school. Acad Med 1998; 73: 1149-58.

30. Roter DL, Hall JA. Why physician gender matters in shaping the physician-patient relationship. J Women's Health 1998; 7: 1093-7.

31. Doherty E, McGee HM, O'Boyle CA, Shannon W, Bury G, Williams A. Communication skills training in undergraduate medicine: attitudes and attitude change. Ir Med J 1992; 85: 104-7.

32. Langille DB, Kaufman DM, Laidlaw TA, Sargeant J, MacLeod H. Faculty attitudes towards medical communication and their perceptions of students' communication skills training at Dalhousie University. Med Educ 2001; 35: 548-54.

33. Liddell MJ, Davidson SK. Student attitudes and their academic performance: is there any relationship? Med Teach 2004; 26: 52-6.

34. Rees C, Sheard C. Evaluating first-year medical students' attitudes to learning communication skills before and after a communication skills course. Med Teach 2003; 25: 302-7. 